\title{
Punching shear capacity of reinforced concrete slabs with headed shear studs
}

\section{Hoang, Linh Cao; Pop, Anamaria}

Published in:

Magazine of Concrete Research

Link to article, DOI:

10.1680/macr.15.00033

Publication date:

2015

Document Version

Publisher's PDF, also known as Version of record

Link back to DTU Orbit

Citation (APA):

Hoang, L. C., \& Pop, A. (2015). Punching shear capacity of reinforced concrete slabs with headed shear studs. Magazine of Concrete Research, [1500033]. https://doi.org/10.1680/macr.15.00033

\section{General rights}

Copyright and moral rights for the publications made accessible in the public portal are retained by the authors and/or other copyright owners and it is a condition of accessing publications that users recognise and abide by the legal requirements associated with these rights.

- Users may download and print one copy of any publication from the public portal for the purpose of private study or research.

- You may not further distribute the material or use it for any profit-making activity or commercial gain

- You may freely distribute the URL identifying the publication in the public portal

If you believe that this document breaches copyright please contact us providing details, and we will remove access to the work immediately and investigate your claim. 


\title{
Punching shear capacity of reinforced concrete slabs with headed shear studs
}

\author{
Linh C. Hoang PhD \\ Department of Civil Engineering, Technical University Denmark, Lyngby, \\ Denmark
}

Anamaria Pop MSc(Eng)

Department of Bridges, RAMBOLL, Copenhagen, Denmark

Punching shear in slabs is analogous to shear in beams. Despite this similarity, current design codes provide distinctly different methods for the design of shear reinforcement in the two situations. For example, the Eurocode method for beam shear design is founded on the theory of rigid plasticity. To design shear reinforcement in slabs, on the other hand, the engineer must settle for an empirical equation. The aim of the study reported is to demonstrate that it is possible in a simple manner to design shear reinforcement in slabs based on the same rigid-plasticity foundation as for beam shear design. For this purpose, an extension of the upper-bound crack sliding model is proposed. This involves analysis of sliding mechanisms in yield lines developed both within and outside the zone with shear reinforcement. Various types of headed shear studs were considered. The results obtained using the model were compared with a large number of published test results, and satisfactory agreements were found.

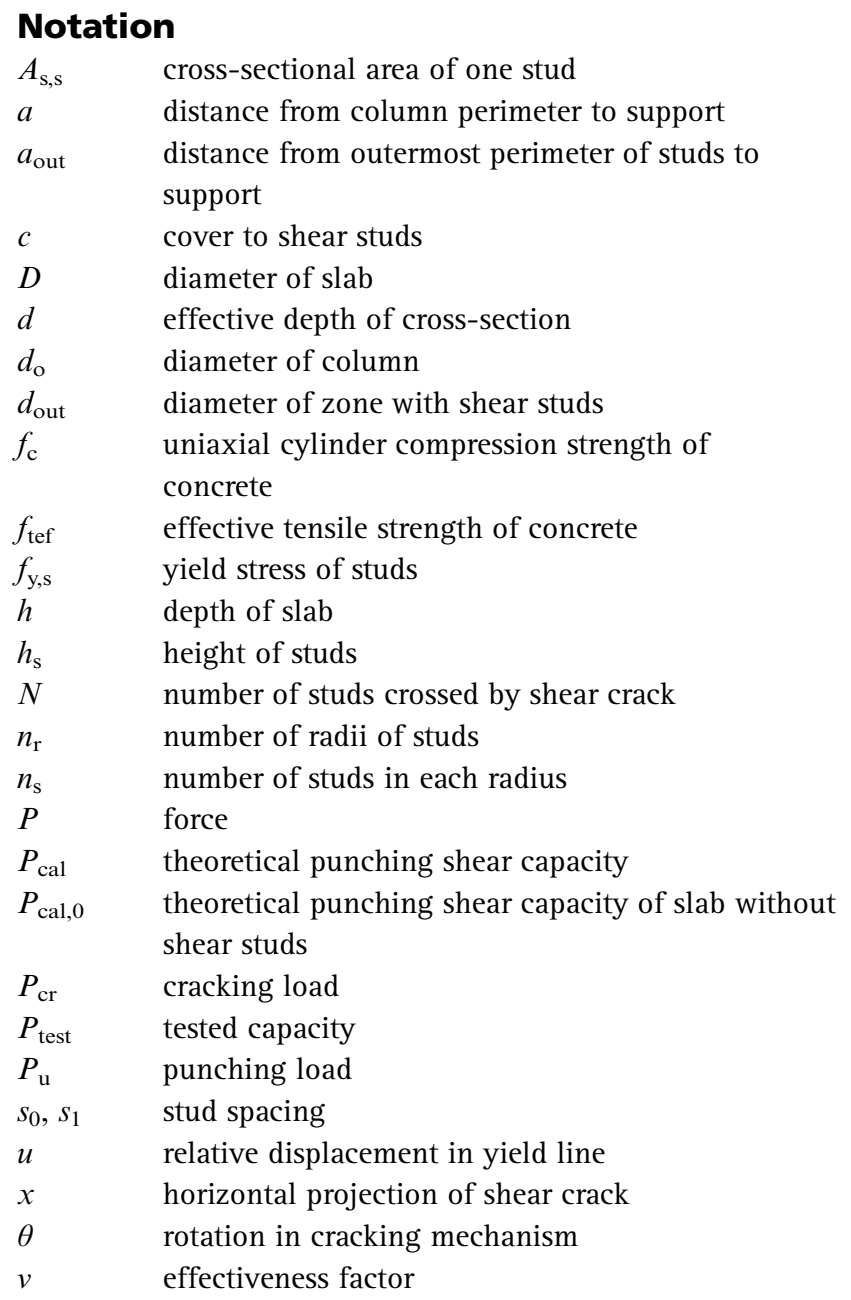

$\begin{array}{ll}\rho & \begin{array}{l}\text { flexural reinforcement ratio (determined on the } \\ \text { basis of full depth } h \text { ) }\end{array} \\ \rho_{\mathrm{t}} & \begin{array}{l}\text { nominal shear reinforcement ratio (Equation 11) } \\ \varphi\end{array} \\ \text { angle of friction }\end{array}$

\section{Introduction}

The punching shear capacity of reinforced concrete slabs is of great relevance for practical design and has therefore received much research attention over the past five decades. The earlier investigations mainly concerned slabs without shear reinforcement. A review of those works may be found in, for example, fib Bulletin No. 12 (fib, 2001). Important reference works include those by Kinnunen and Nylander (1960) and Nielsen et al. (1978).

Similar to reinforced concrete beams, the strength and the deformation capacity of slabs can be improved if shear reinforcement is provided. Ideally, a sufficient content of shear reinforcement should turn the structure from being shear critical to be governed by flexural failure. In practice, shear reinforcement in the form of closed stirrups is difficult to handle in two-way spanning slabs. A popular alternative is, therefore, headed shear studs (Figures 1(a) to 1(c)), which can be easily installed after placement of the flexural reinforcement. Shear studs are often arranged in a radial or cruciform configuration (Figures 1(d) and 1(e)). For fast installation, the studs are sometimes delivered pre-welded to steel rails. In this case, the rails with studs must be installed before the flexural reinforcement at the top face is placed.

Most design standards deal with shear-reinforced slabs in a different way than for shear-reinforced beams, even though 


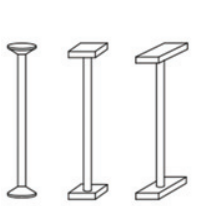

(a)

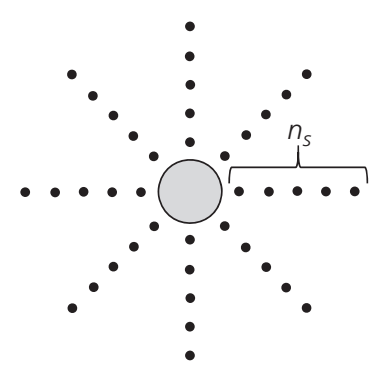

(d)

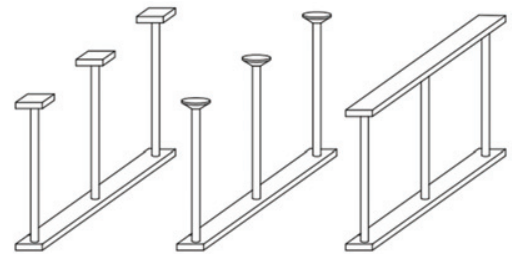

(c)

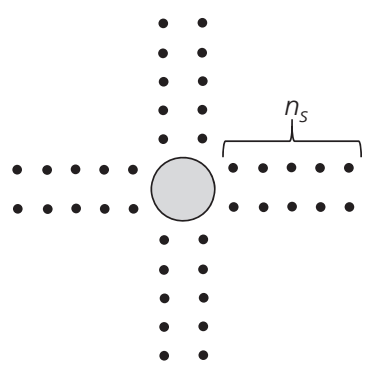

(e)
Figure 1. (a)-(c) Types of shear stud; (d)-(e) typical arrangements in slabs

punching shear in slabs is a two-way analogy to shear in beams. In Eurocode 2 (BSI, 2005) for instance, design of beam shear reinforcement is grounded on a rigid-plastic lower-bound model (Nielsen et al., 1978), while design of shear reinforcement in slabs follows a purely empirical equation. Empirical methods may be easy to use and correlate well with selected tests. However, the disadvantage of these methods is that they do not provide the engineer with an explanation of the mechanical phenomena involved. Moreover, it is difficult to extrapolate empirical equations to non-standard cases. In the recently published Model Code 2010 (fib, 2013), a significant step away from the purely empirical approach has been taken. The Model Code 2010 provisions on punching shear are based on the critical shear crack theory. This theory was originally developed for non-shear-reinforced members, and has been extended to cover slabs with shear reinforcement (Fernández and Muttoni, 2009; Muttoni and Schwartz, 1991). Many physical phenomena are taken into account in this model, including the influence of crack width on the shear resistance of the critical crack as well as on the state of stress in the shear studs. One of the main assumptions in this context is that the critical shear crack has an inclination of $45^{\circ}$. As a consequence, only shear reinforcement placed within the extent of the ' $45^{\circ}$ shear crack' may be taken into account.

The investigation presented in this paper is based on a rigidplastic upper-bound approach. This choice of approach was motivated by the fact that the results obtained would be grounded on the same theoretical basis as the Eurocode 2 method for beam shear design. Furthermore, in a rigid-plastic approach, the inclination of the critical yield line is found by calculation, and may therefore have a value different from $45^{\circ}$.
This means that, within the framework of rigid-plasticity, it is possible to capture the fact that the concrete contribution will vary depending on the shear reinforcement ratio. In addition, shear reinforcement outside the extent of a $45^{\circ}$ shear crack may also be taken into account, which is an advantage.

The starting point of the investigation was the crack sliding model (CSM) (Zhang, 1997), which draws on the classical upper-bound approach (Nielsen et al., 1978), and, in addition, takes into account the possibility of sliding failures in initial cracks. In the present study, crack sliding failures within as well as outside the zone with shear reinforcement were considered. The results of the model were compared with the results of relevant tests published in the literature. Satisfactory agreement was obtained without the need to calibrate the model parameters by undertaking punching tests.

\section{Principles of the crack sliding model}

The CSM was originally developed by Zhang (1997) for beam shear problems, and has been further developed by Hoang (2006) to deal with punching shear in slabs without shear reinforcement. This section provides a brief summary of the principles behind the CSM, and demonstrates how it is applied to slabs without shear reinforcement. For details, the reader is referred to Hoang (2006) or Nielsen and Hoang (2011).

Unlike the classical upper-bound approach, the CSM differentiates between yield lines formed in uncracked concrete and yield lines formed in cracked concrete. Yield lines are lines of discontinuity in displacement, and the phenomenon of sliding yield lines formed in cracked concrete can, for example, be interpreted from the experimental research carried out by Muttoni (1990). Muttoni showed that when the critical shear crack is formed, the relative displacement is mainly perpendicular to the surface of the crack. At the onset of the shear failure, however, the relative displacement in the crack has a component parallel to the crack. Due to this change in relative displacement, the sliding resistance along the crack is mobilised. In terms of plastic theory, the crack is transformed into a sliding yield line.

According to the CSM, the position of the critical yield line can be determined by combining a cracking criterion with a crack sliding criterion. The first criterion is used to calculate the load required to develop a certain shear crack, while the second criterion is used to evaluate the possibility of a sliding failure in the same crack. If the sliding resistance is equal to the cracking load, a shear failure may take place immediately after cracking. However, if the sliding resistance turns out to be larger, the considered crack is not critical. The applied load may, in this case, increase further, which then leads to the development of new shear cracks. The cracking load $P_{\text {cr }}$ and the crack sliding load $P_{\mathrm{u}}$ are derived by considering geometrically possible mechanisms. 


\section{Offprint provided courtesy of www.icevirtuallibrary.com Author copy for personal use, not for distribution}

Figure 2 illustrates an axisymmetric reinforced slab, simply supported along the perimeter $D$ and loaded at the centre by a force $P$. The load is applied via a column with diameter $d_{\mathrm{o}}$, and the slab is assumed to be sufficiently reinforced with respect to bending and torsional moments. A punching failure is assumed to take place in a circumferential shear crack, which for simplification is assumed to have the form of a conical surface (in Figure 2, $x$ is the horizontal projection of the crack). The failure mechanism is idealised as an upward punch of the truncated conical concrete block. An upper bound for the punching load $P_{\mathrm{u}}(x)$ can be determined by use of the work equation, and by assuming that the cracked concrete obeys the modified Coulomb failure criterion and the normality condition of plastic theory. The solution is (Hoang, 2006)

1. $P_{\mathrm{u}}=\frac{\pi}{2} v f_{\mathrm{c}}\left(d_{\mathrm{o}}+x\right)\left[\left(x^{2}+h^{2}\right)^{0.5}-x\right]$

where the effectiveness factor $v$ takes into account the fact that concrete is not perfectly rigid-plastic as assumed in the calculations. In addition, the effectiveness factor in the CSM also accounts for the reduced sliding strength of cracks compared with that of uncracked concrete. In a condensed form, the effectiveness factor appears as follows:

2. $v=\frac{0 \cdot 44}{f_{\mathrm{c}}^{0.5}}\left[1+\frac{1}{h^{0.5}}\right](1+26 \rho)$

where $f_{\mathrm{c}}$ is in megapascals and $h$ is in metres. Here, the parameter $\rho$ is the flexural reinforcement ratio. A detailed discussion of the physical reasons behind this factor has been given by Zhang (1997), who used the equation for rectangular beams. When Equation 2 is applied to two-way spanning slabs, the reinforcement ratio may be taken as $\rho=\left(\rho_{x} \rho_{y}\right)^{0.5}$, where $\rho_{x}$ and $\rho_{y}$ are the reinforcement ratios in two orthogonal directions (Hoang, 2006).

For a punching failure to take place as crack sliding, the crack has to exist prior to failure. Hence, one must verify that it is

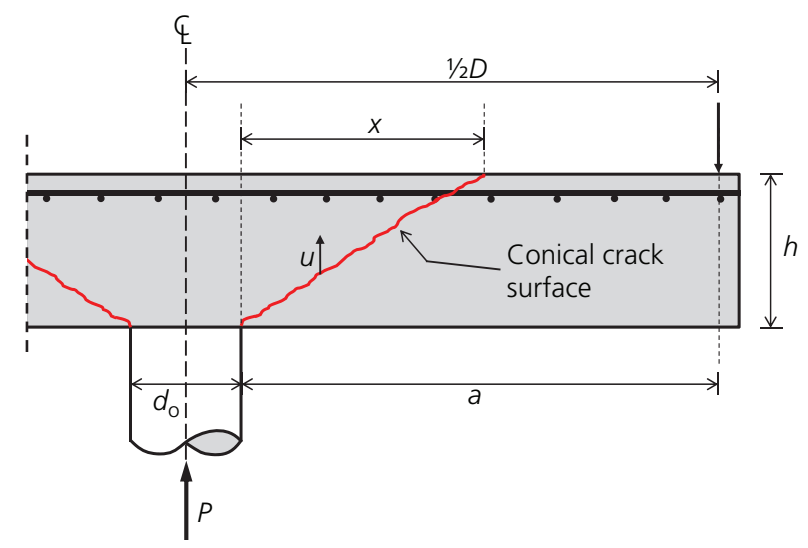

Figure 2. Punching mechanism in a slab without shear studs possible to develop the crack at a load that is lower or equal to the load level required to cause shear failure in the crack. In this context, the cracking load is calculated based the cracking mechanism shown in Figure 3. Note that the circumferential shear crack has to be accompanied by a system of radial flexural cracks to make the cracking mechanism geometrically possible. By using the upper-bound technique for this cracking mechanism, it may be shown that the cracking load is given by (Hoang, 2006)

3. $P_{\mathrm{cr}}=\frac{2 \pi}{a} f_{\mathrm{tef}}\left[\left(x^{2}+h^{2}\right)\left(\frac{d_{\mathrm{o}}}{4}+\frac{x}{3}\right)+h^{2}\left(\frac{a}{2}-\frac{x}{3}\right)\right]$

When deriving this solution, the cracking moment of the cross-section has been assumed to be independent of the flexural reinforcement (which is a normal assumption). The cracking moment thus depends only on the tensile strength of the concrete and the height of the cross-section. In the solution, the so-called 'effective plastic tensile strength' of concrete $f_{\text {tef }}$ has been used. For beam shear, Zhang (1997) proposed the following expression, which was also adopted in the present study

4. $f_{\text {tef }}=0 \cdot 156 f_{c}^{2 / 3}\left(\frac{h}{0 \cdot 1}\right)^{-0 \cdot 3}$

where $h$ is in metres and $f_{\mathrm{c}}$ is in megapascals. An example of the variation in $P_{\mathrm{u}}(x)$ and $P_{\mathrm{cr}}(x)$ versus $x$ is shown in Figure 4, which also offers a simple explanation of the punching failure process in slabs without shear reinforcement. At lower load levels, steep shear cracks with a small horizontal projection $x$ can be formed. Because the sliding resistance of these cracks is larger than the load required to form them, sliding failure cannot occur. However, when the applied load leading to the formation of a shear crack is equal to the sliding resistance of that same

(a)

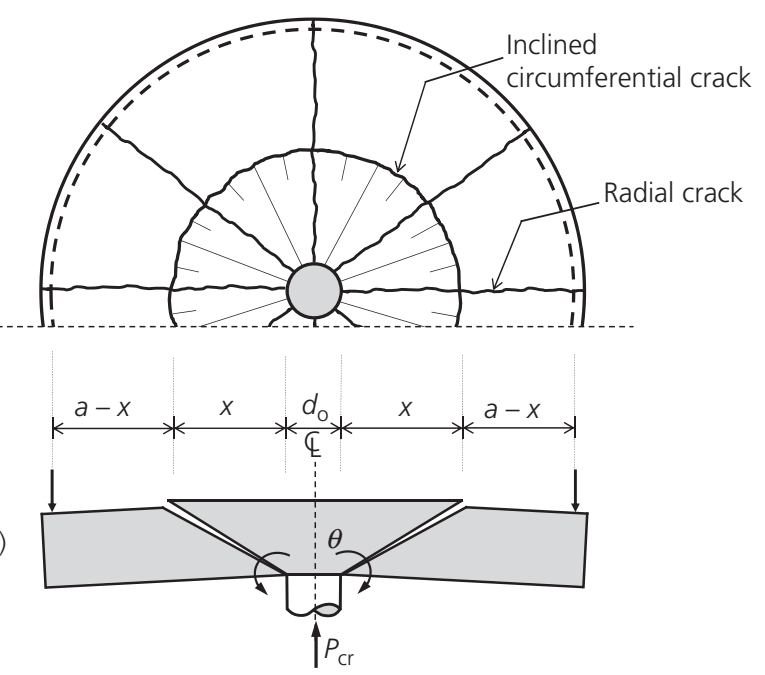

Figure 3. Cracking mechanism in a slab without shear studs $\eta$ 


\section{Offprint provided courtesy of www.icevirtuallibrary.com Author copy for personal use, not for distribution}

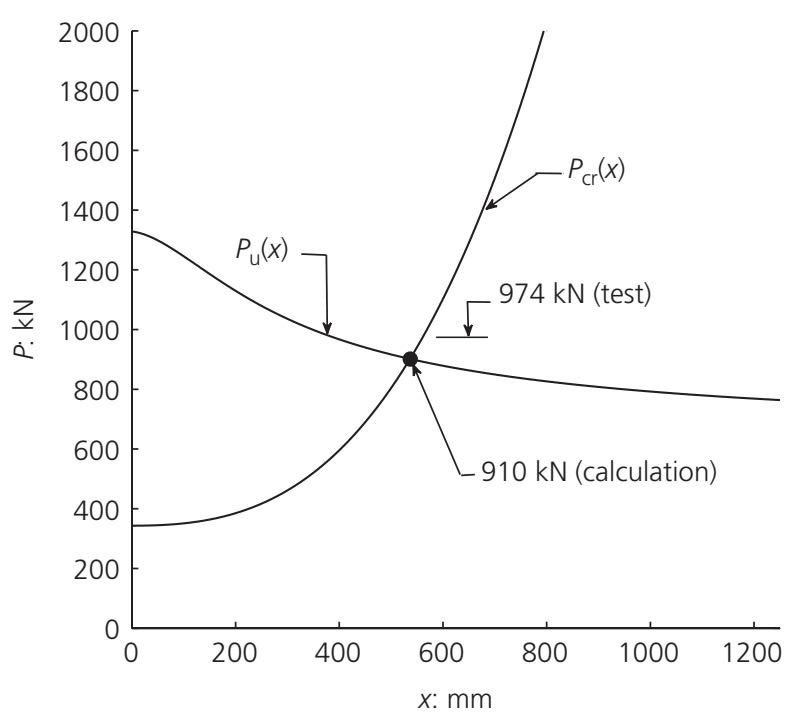

Figure 4. Variation in the punching and cracking load as a function of $x$ (parameters correspond to test specimen PV1 reported by Lips et al. (2012))

crack, punching failure will occur. Thus, this load level must be taken as the punching capacity, and it is found graphically as the intersection of the two curves representing $P_{\mathrm{u}}$ and $P_{\mathrm{cr}}$.

Analytically, the capacity is found by solving $P_{\mathrm{u}}(x)=P_{\mathrm{cr}}(x)$ with respect to $x$, and then inserting the result into Equation 1. The solution has to fulfil the constraints: $0 \cdot 75 h \leq$ $x \leq a$. The upper constraint is due to geometry (the crack needs to be within the shear span $a$ ), while the lower constraint is a consequence of the normality condition of plastic theory. This condition dictates that the angle between the relative displacement at failure and the shear crack cannot be smaller than the internal angle of friction, which for concrete is taken as $\varphi=\arctan 0 \cdot 75$ (Nielsen and Hoang, 2011). The mentioned constraints mean that if $x$ is found to be less than $0.75 h$, then $x=0.75 h$ has to be inserted in Equation 1 to find the punching capacity. On the other hand, if $x$ is found to be larger than $a$, then $x=a$ must be used.

The model outlined was shown to give good agreement with a large number of test results for slabs without shear reinforcement (Hoang, 2006).

\section{Application of CSM to slabs with shear studs}

The CSM has recently been extended to deal with slabs reinforced with shear studs arranged in either a radial or a cruciform configuration (Pop, 2014). It is normal to place shear studs only within a limited area around the column. For this reason, it is necessary to consider potential failures within as well as outside the shear-reinforced zone. In the following, two pure punching mechanisms are analysed.

\section{Mechanism I - failure within zone containing shear studs}

As in the previous section, a sliding failure is assumed to take place in a circumferential shear crack that is idealised as a conical surface (Figure 5). The shear crack crosses a number of shear studs. Because of the displacement discontinuity in the yield line, these studs will have to yield and thus dissipate plastic energy. In this context, it is noted that yielding of the shear studs, as indicated by experimental studies, can be achieved if the studs are well anchored. For instance, Elgabry and Ghali (1990) reported that circular or square anchor plates with an area of at least ten times the cross-sectional area of the stud are sufficient to develop yielding (410 MPa) in the studs. According to the investigations by Seible et al. (1980), anchorage is adequate and leads to yielding (500 MPa) of the shear studs when the diameter of the circular head is four times the stem diameter.

The total number of studs crossed by the shear crack will, of course, be a function of the horizontal projection $x$. With reference to Figure 5, it may now be shown that the following algorithm can be used to calculate the number of studs $N(x)$ crossed by the shear crack. For $\eta x \leq s_{0}$

\section{5. $\quad N(x)=0$}

For $s_{0}+(i-1) s_{1}<\eta x \leq s_{0}+i s_{1} ; i=1,2,3, \ldots, n_{\mathrm{s}}$

6a. $\quad N(x)=n_{\mathrm{r}} i \quad$ if $\quad \frac{x}{h} \leq \frac{s_{0}}{c}$

6b. $\quad N(x)=n_{\mathrm{r}}(i-1) \quad$ if $\quad \frac{s_{0}}{c}<\frac{x}{h} \leq \frac{s_{0}+s_{1}}{c}$

6c. $\quad N(x)=n_{\mathrm{r}}(i-2) \quad$ if $\quad \frac{s_{0}+s_{1}}{c}<\frac{x}{h}$

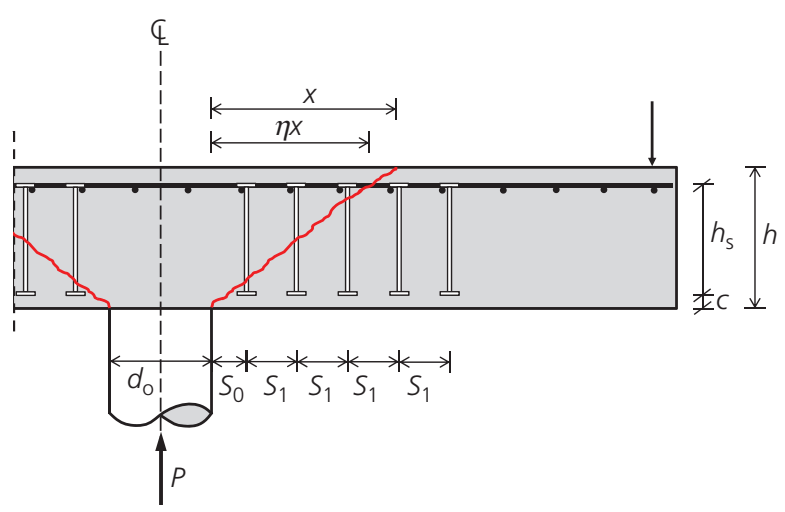

Figure 5. Punching failure within the zone containing shear studs 


\section{Offprint provided courtesy of www.icevirtuallibrary.com Author copy for personal use, not for distribution}

Here, $n_{\mathrm{r}}$ is the number of radii of studs (e.g. $n_{\mathrm{r}}=8$ for the arrangements shown in Figures 1(d) and 1(e)), and $n_{\mathrm{s}}$ is the number of studs within each radius. The parameter $\eta(\leq 1)$ is defined as

7. $\eta=\frac{h_{\mathrm{s}}+c}{h}$

This parameter takes into account the fact that the height of the studs $h_{\mathrm{s}}$ is smaller than the height of the slab. Therefore, there may only be shear studs within the distance $\eta x$ for the crack to intersect. It should be noted that Equation $6 \mathrm{~b}$ takes into account the case where the inclination of the shear crack is so small (i.e. large value of $x$ ) that the first perimeter of studs will escape intersection with the shear crack. Similarly, Equation $6 \mathrm{c}$ accounts for the case where both the first and the second perimeter of studs are not intersected by the crack. It may be shown that omitting more than two studs in each radius is not relevant.

Having established the algorithm to keep track of the number of studs to be included, it is now possible to set up the work equation leading to an upper bound for the punching capacity. The result is as follows.

8. $\quad P_{\mathrm{u}}(x)=\underbrace{\frac{\pi}{2} v f_{\mathrm{c}}\left(d_{\mathrm{o}}+x\right)\left[\left(x^{2}+h^{2}\right)^{0.5}-x\right]}_{\text {Concrete contribution }}+\underbrace{N(x) A_{\mathrm{s}, \mathrm{f}} f_{\mathrm{y}, \mathrm{s}}}_{\text {Shear stud contribution }}$

The first term in Equation 8 is, of course, identical to Equation 1. Note that Equation 8 differs from Equation 1 in two distinct ways. First, the curve representing Equation 8 will be discontinuous with respect to $x$. There is a jump (corresponding to $\left.n_{\mathrm{r}} A_{\mathrm{s}, \mathrm{s}} f_{\mathrm{y}, \mathrm{s}}\right)$ on the curve whenever a new perimeter of studs is intersected. Second, Equation 8 may have a minimum value within the range $0 \leq x \leq a$, while Equation 1 just decreases monotonically. The variation in Equation 8 is illustrated for two characteristic cases in Figure 6. For illustration, the separate contributions from the concrete and from the shear studs have been plotted as dashed lines. Note that the cracking load $P_{\text {cr }}(x)$ has not been plotted. The cracking load is, as explained below, not relevant in this case.

According to the description in the previous section, the critical shear crack should, in principle, be found by the intersection between the $P_{\mathrm{u}}(x)$ curve and the $P_{\mathrm{cr}}(x)$ curve. In this context, $P_{\mathrm{cr}}(x)$ may be determined by means of Equation 3, thus neglecting the effects of shear reinforcement on the cracking load. This procedure, however, turns out to be unnecessary when a shear failure within the zone containing studs is considered. Based on a large parametric study (Pop, 2014), it has been found that the $P_{\mathrm{u}}(x)$ curve according to Equation 8 will always lie above the $P_{\mathrm{cr}}(x)$ curve for shear reinforcement ratios usually met with in practice. The two curves will, therefore, not

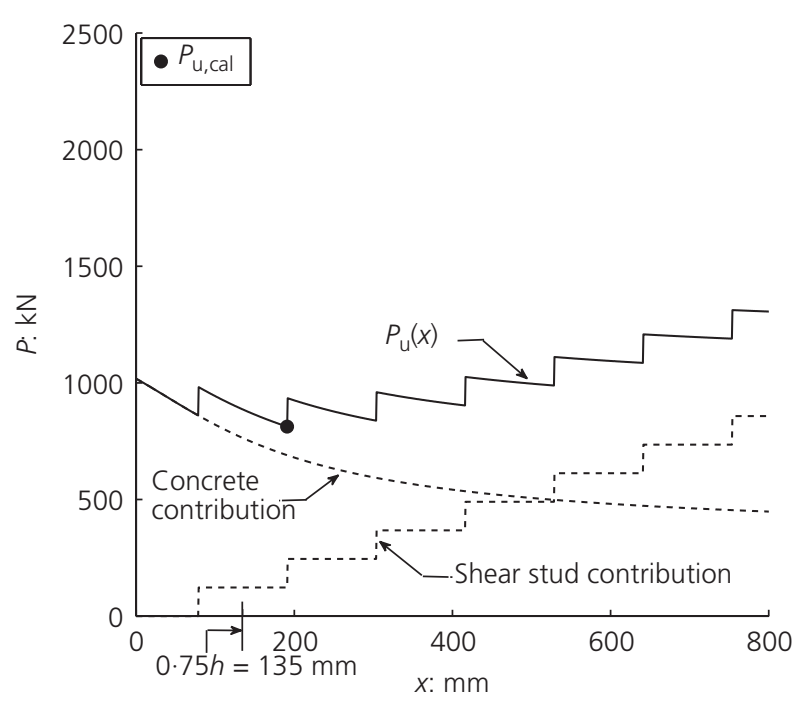

(a)

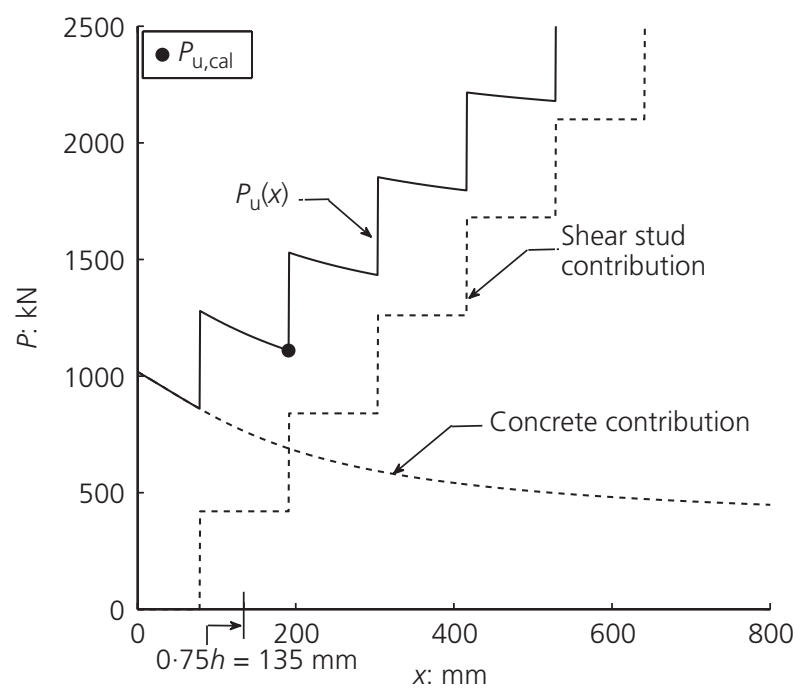

(b)

Figure 6. Schematic variation in $P_{\mathrm{u}}(x)$ versus $x$ for slabs with (a) a low number and (b) a high number of shear studs

intersect. This basically means that all potential shear cracks have already been developed at load levels that are lower than the load, which eventually will cause punching failure. A similar situation is also found when the CSM is applied to lightly shear-reinforced beams (Nielsen and Hoang, 2011). Hence, with reference to Figure 6(a), the punching capacity must be taken as the minimum value on the $P_{\mathrm{u}}(x)$ curve. This point is marked on the figure by a dot. The content of shear reinforcement may, in some cases, be so large (e.g. in many of the published tests), that the global minimum on the $P_{\mathrm{u}}(x)$ curve is located at $x<0.75 \mathrm{~h}$. In such situations, the punching capacity must be taken as the smallest value that occurs on the $P_{\mathrm{u}}(x)$ curve for $x \geq 0.75 h$ (see the explanation of the normality condition in the previous section). This is 


\section{Offprint provided courtesy of www.icevirtuallibrary.com Author copy for personal use, not for distribution}

marked by the dot in Figure 6(b). Note that parameters corresponding to test specimen C1 reported by Ferreira et al. (2014) have been used to plot Figure 6(b). The same parameters were used to plot Figure 6(a), except for $\rho_{\mathrm{t}}=0 \cdot 18 \%$.

The procedure described above may be called a 'discrete' approach because it takes into account the effect of finite stud distances. This effect, which is not included in existing methods, may be significant in cases where the stud spacing is large. If, however, the stud distance is small compared with the height of the slab, a classical smeared approach can be used. Basically, the number of studs crossed by the shear crack may, in this approach, be approximated by a continuous function $N(x)=\eta x / s_{1}$, leading to a continuous function for $P_{\mathrm{u}}(x)$. Calculations based on a smeared approach have also been investigated in detail by Pop (2014). In the present study, however, the scope was confined to results obtained using the discrete approach.

\section{Mechanism II - failure outside the zone containing shear studs}

Depending on the extent of the shear-reinforced zone, a failure outside this zone might occur. The original procedure of the CSM may be used in such situations. As illustrated in Figure 7, the circumferential shear crack to be considered is now assumed to begin from the last perimeter of studs.

By following the procedure outlined for slabs without shear reinforcement, the punching capacity can be found by solving $P_{\mathrm{u}}(x)=P_{\mathrm{cr}}(x)$ with respect to $x$. In this context, $P_{\mathrm{u}}(x)$ has to be determined as follows.

9. $\quad P_{\mathrm{u}}=\frac{\pi}{2} v f_{\mathrm{c}}\left(d_{\text {out }}+x\right)\left[\left(x^{2}+h^{2}\right)^{0.5}-x\right]$

This equation is similar to Equation 1, except that $d_{\text {out }}$ now replaces $d_{\mathrm{o}}$. Likewise, the cracking load $P_{\mathrm{cr}}(x)$ must be determined by inserting $d_{\text {out }}$ and $a_{\text {out }}$ instead of $d_{\mathrm{o}}$ and $a$, respectively, into Equation 3 . The parameters $d_{\text {out }}$ and $a_{\text {out }}$ are defined in Figure 7. The equation for $P_{\mathrm{cr}}(x)$ is

10. $P_{\text {cr }}=\frac{2 \pi}{a_{\text {out }}} f_{\text {tef }}\left[\left(x^{2}+h^{2}\right)\left(\frac{d_{\text {out }}}{4}+\frac{x}{3}\right)+h^{2}\left(\frac{a_{\text {out }}}{2}-\frac{x}{3}\right)\right]$

According to the explanations provided above, the solution obtained when solving $P_{\mathrm{u}}(x)=P_{\mathrm{cr}}(x)$ in this case is valid only if it fulfils the condition: $0 \cdot 75 h \leq x \leq a_{\text {out }}$. If $x$ is smaller than $0 \cdot 75 \mathrm{~h}$, this limit must be used to calculate $P_{\mathrm{u}}$. Finally, if $x$ is larger than $a_{\text {out }}$, then $x=a_{\text {out }}$ must be used.

\section{Comparison with test results}

In the present study, calculations were carried out and compared with 58 relevant test results found in the literature

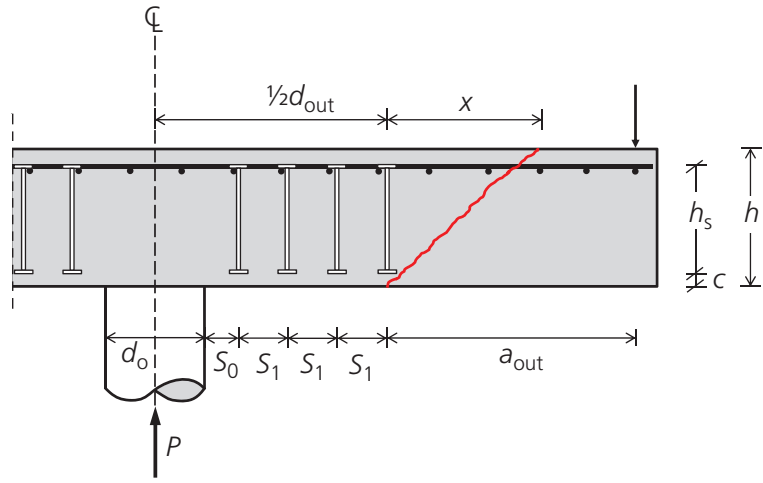

Figure 7. Punching failure outside the zone containing shear studs

(Beutel, 2002; Birkle and Dilger, 2008, 2009; Broms, 2007; Ferreira et al., 2014; Lips et al., 2012; Moreno and Sarmento, 2013; Musse, 2004; Regan and Samadian, 2001; Trautwein, 2006; Vaz et al., 2009). The range of a number of important parameters is shown later in Figure 10. A detailed review of the tests has been given in the thesis by Pop (2014). The tests considered include slabs with double-headed studs, single-headed studs welded on steel rails, and double rail studs. In some of the tests the loading footprint was quadratic. In these cases, the side length of the quadratic footprint was used as the diameter $d_{\mathrm{o}}$ when performing the calculations. For the tests considered, the boundary conditions comply (either approximately or exactly) with the assumption of a circular support perimeter.

The correlation between the tests and the calculations is shown in Figure 8. In the plots, the tests have been grouped according to test series and according to predicted failure mechanism. As can be seen, mechanism I (which is also the most important one in relation to dimensioning) is critical in the majority of the tests. The mean value of the ratio $P_{\mathrm{u} \text {,test }} / P_{\mathrm{u}, \mathrm{cal}}$ was found to be $0 \cdot 88$, and the standard deviation was $0 \cdot 14$. Hence, on average, the model (providing upper bounds for the capacity) overestimates the load-carrying capacity by $13 \%$.

In Figure 9 the ratio $P_{\mathrm{u}, \text { test }} / P_{\mathrm{u}, \mathrm{cal}}$ is plotted against the ratio $P_{\mathrm{u}, \mathrm{cal}} / P_{\mathrm{u}, 0}$, where $P_{\mathrm{u}, 0}$ denotes the calculated punching capacity of a similar slab without shear reinforcement. This plot is intended to show how the correlation varies, when the relative contribution from the shear studs varies. As can be seen, the range of the theoretical strength increase (when shear studs are supplied) is from about $P_{\mathrm{u}, \mathrm{cal}} / P_{\mathrm{u}, 0}=1 \cdot 3$ to $P_{\mathrm{u}, \mathrm{cal}} / P_{\mathrm{u}, 0}=3 \cdot 3$. This means that for the most heavily shear-reinforced test specimens more than three times the basic strength could theoretically be obtained. From the plot it can be observed that the ratio $P_{\mathrm{u}, \text { test }} / P_{\mathrm{u}, \mathrm{cal}}$ has a tendency to decrease moderately when the ratio $P_{\mathrm{u}, \mathrm{cal}} / P_{\mathrm{u}, 0}$ increases. In fact, for the six tests where $P_{\mathrm{u}, \mathrm{cal}} /$ $P_{\mathrm{u}, 0}$ is between $3 \cdot 0$ and $3 \cdot 5$, the mean value of $P_{\mathrm{u} \text {,est }} / P_{\mathrm{u}, \text { cal }}$ was found to be 0.77 (standard deviation 15\%). This means that 


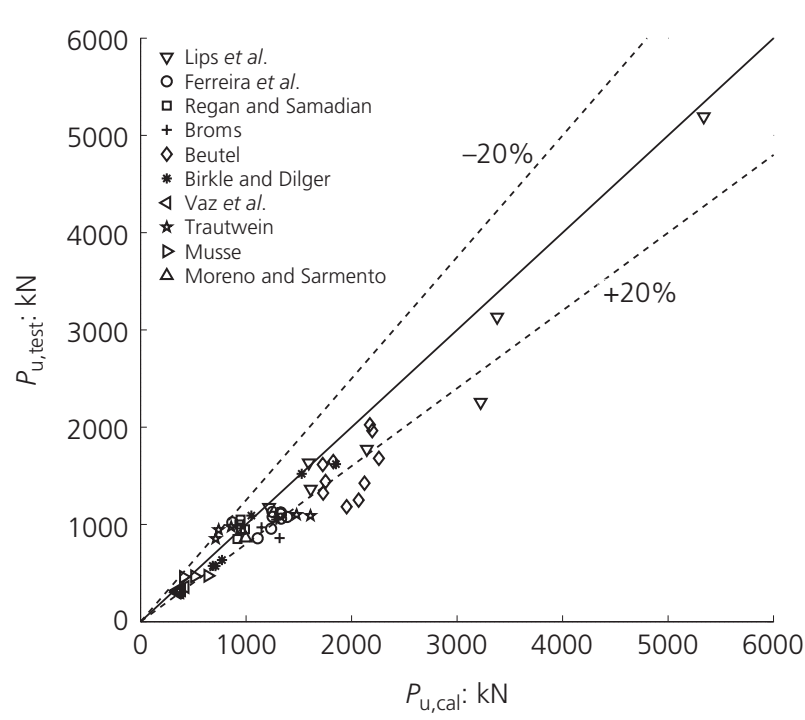

(a)

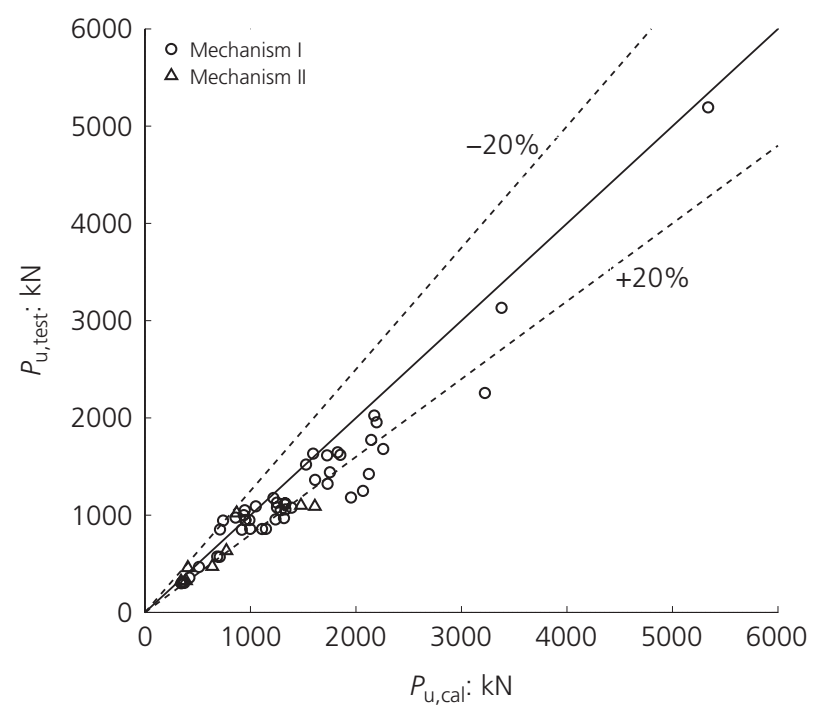

(b)

Figure 8. Comparison of the tests and the calculations

for these six heavily shear-reinforced specimens the model overestimates the observed results by, on average, 30\%. This overestimation is larger than the overall result $(13 \%$, as mentioned in the above) and may most probably be explained by the fact that the model does not directly take into account the effect of crack width on the shear resistance of cracks. It is well known that the shear resistance of cracks depends on the crack opening (see, for example, Fernández and Muttoni, 2009). In this context, it is noted that the effectiveness factor $v$ of the CSM was originally calibrated using the results of shear tests on beams without stirrups (Zhang, 1997). In non-shear-reinforced members, shear failure usually takes place immediately after crack formation (see the explanation of the CSM above), while in shear-reinforced members, failure takes place in an initial

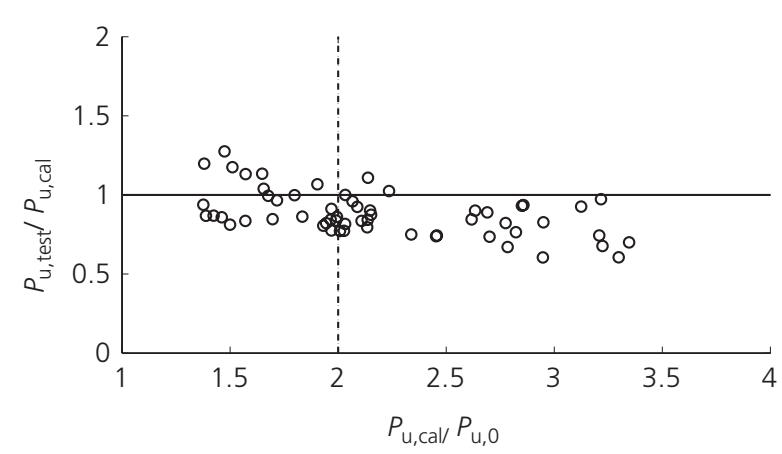

Figure 9. $P_{\mathrm{u}, \text { test }} / P_{\mathrm{u}, \mathrm{cal}}$ plotted against the theoretical strength increase ratio (relative to the strength of the slab without studs, $\left.P_{\mathrm{u}, 0}\right)$

crack developed at an earlier loading stage. Therefore, the crack width prior to failure is larger in shear-reinforced members than in non-shear-reinforced members (Fernández and Muttoni, 2009). The effect of shear crack width is only taken into account indirectly in the CSM, where $v$ depends on the flexural reinforcement ratio (which is one of the main parameters that control the crack widths). Hence, the above-mentioned overestimation for the six heavily shear-reinforced specimens can most probably be reduced if the model is refined in such a way that the effectiveness factor becomes a descending function of the shear crack width. However, such a refinement would require an iterative procedure to determine the punching capacity.

To determine how accurate the model predictions are, the ratio $P_{\mathrm{u} \text {,test }} / P_{\mathrm{u}, \mathrm{cal}}$ was plotted against a number of key parameters, as shown in Figure 10, which gives plots of $P_{\mathrm{u}, \text { test }} / P_{\mathrm{u}, \text { cal }}$ against $h, \rho_{\mathrm{t}}, f_{\mathrm{c}}$ and $f_{\mathrm{y}, \mathrm{s}}$. Note that a unique value for the shear reinforcement ratio cannot be defined for shear studs arranged in a radial or cruciform configuration. Therefore, as a measure of the content of shear reinforcement, the following nominal ratio is adopted (similar to the ratio used by Lips et al., 2012)

$$
\text { 11. } \rho_{\mathrm{t}}=\frac{n_{\mathrm{r}} A_{\mathrm{s}, \mathrm{s}}}{s_{1} \pi\left(d_{\mathrm{o}}+d\right)}
$$

From Figure 10 it can be seen that the model is reasonably robust in terms of accuracy and scatter when the different parameters are varied. Of particular interest is the plot showing $P_{\mathrm{u} \text {,test }} / P_{\mathrm{u}, \mathrm{cal}}$ against $f_{\mathrm{y}, \mathrm{s}}$. It appears that the accuracy of model is not particularly sensitive with respect to the yield strength of the studs used in the tests. This indicates that it is reasonable (in calculations) to assume yielding in all studs crossed by the shear crack.

Overall, the obtained result - especially the standard deviation - is judged to be satisfactory when considering the simplicity of the model and the fact that the parameters $v$ and $f_{\text {tef }}$ have been adopted without modification (as mentioned, 


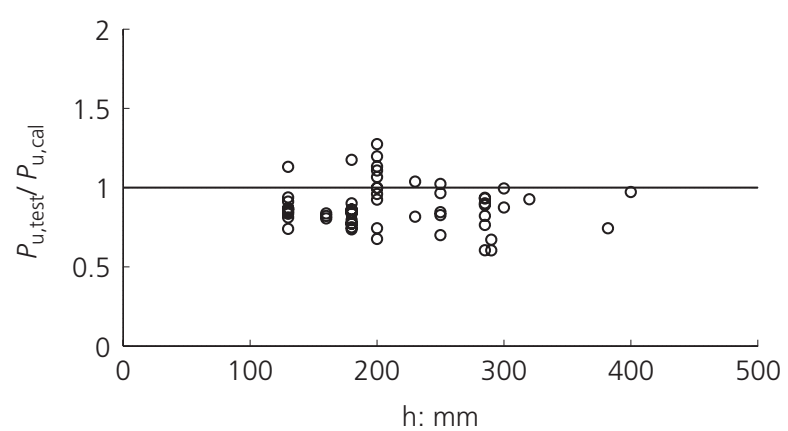

(a)

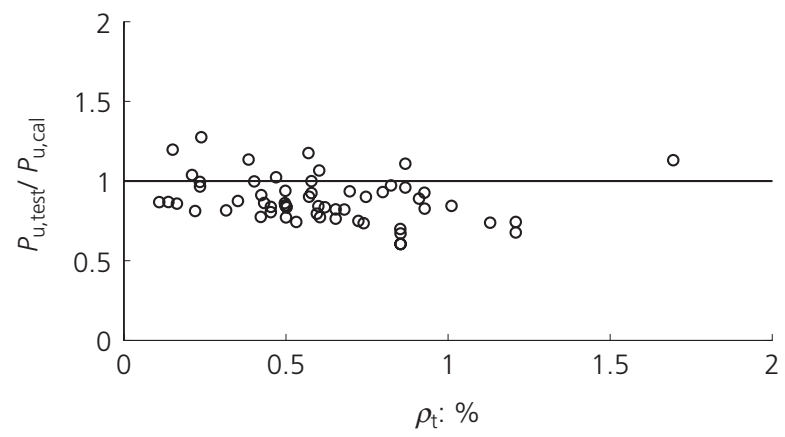

(b)

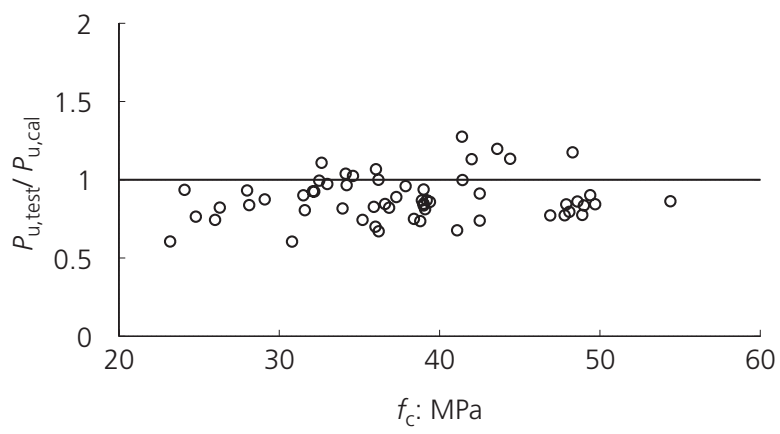

(c)

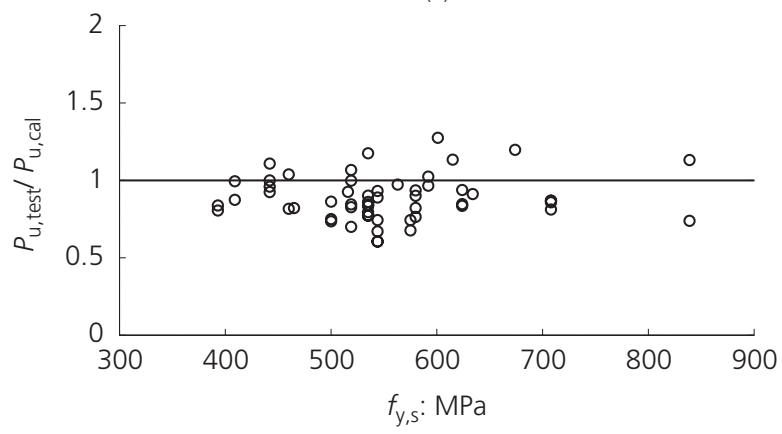

(d)

Figure 10. $P_{\mathrm{u}, \text { test }} / P_{\mathrm{u}, \text { cal }}$ plotted against (a) $h,(\mathrm{~b}) \rho_{\mathrm{t}}(\mathrm{c}) f_{\mathrm{c}}$ and $(\mathrm{d}) f_{\mathrm{y}, \mathrm{s}}$

these parameters were originally calibrated using beam tests (Zhang, 1997)). As discussed above, better agreement with tests may most probably be obtained if the model is refined; for example, by working with an effectiveness factor $v$ that is directly dependent on the shear crack width. This would, however, make the model complicated to use. For the practical application of the model in its current form, a more pragmatic approach may be adopted. This could, for instance, involve a simple multiplication of the calculated punching capacity by a factor 0.88 to account for the average overestimation of the model (see the result of the model prediction above). In addition, an upper limit for the allowable strength increase may be introduced (e.g. $\left.P_{\mathrm{u}, \mathrm{cal}} / P_{\mathrm{u}, 0} \leq 2\right)$, regardless of how high the theoretical strength increase due to studs is found to be. In this context, it is important to observe that below a value of $P_{\mathrm{u}, \mathrm{cal}} / P_{\mathrm{u}, 0}=2$, the plot in Figure 9 does not show any significant change in the accuracy of the model prediction. Furthermore, it should be noted that, in practical design, a strength increase up to twice the basic strength (i.e. without shear reinforcement) will be sufficient in many cases.

\section{Conclusions}

An extension of the plasticity-based CSM to predict the punching shear capacity of reinforced concrete slabs with headed shear studs has been described. Simple formulae for the cracking load and the crack sliding load have been presented. An algorithm taking into account the finite stud spacing has been developed to include the contribution of shear studs. According to the model, the inclination of the critical shear crack depends on the amount of shear reinforcement. This means that the concrete contribution to the punching capacity is not constant as assumed in many code equations. Furthermore, shear studs placed outside the extent of a $45^{\circ}$ shear crack may also affect the punching capacity.

The model provides upper-bound solutions, which on average overestimated the capacity of 58 test specimens by $13 \%$ (standard deviation $0 \cdot 14$ ). This result was obtained without calibration of the model parameters using punching tests, and is therefore judged to be satisfactory. On average, the best agreement with the tests was observed for slabs, where the predicted strength was less than about twice the strength of a similar slab without shear studs.

According to the model it is not necessary to evaluate the cracking load when a failure within the shear-reinforced zone is considered. This makes the model easy to use in practice. What the engineer needs to do is simply to find the minimum value on the $\mathrm{P}_{\mathrm{u}}(x)$ curve for $x>0.75 h$. For failure outside the shear-reinforced zone, the intersection between the $\mathrm{P}_{\mathrm{u}}(x)$ curve and the $\mathrm{P}_{\mathrm{cr}}(x)$ curve needs to be determined in order to find the punching capacity of this zone. In this context, the geometrical parameter $a$ in the model may (as usual) be taken as the average distance from the column face to the perimeter of zero moment when punching of internal columns supporting flat slabs is considered.

This study has only dealt with concentric punching. As an important further development of the model, punching of columns at the edges and corners of flat slabs should be 


\section{Offprint provided courtesy of www.icevirtuallibrary.com Author copy for personal use, not for distribution}

investigated. The main challenge in these eccentric punching problems is to come up with failure mechanisms that capture the effects of moment transfer from column to slab when establishing formulae for $P_{\mathrm{u}}(x)$ and $P_{\mathrm{cr}}(x)$.

\section{REFERENCES}

Beutel R (2002) Punching of Flat Slabs with Shear

Reinforcement at Inner Columns. Rheinisch-Westfalischen Technischen Hochschule, Aachen, Germany.

Birkle G and Dilger WH (2008) Influence of slab thickness on punching shear strength. ACI Structural Journal 105(2): 180-188.

Birkle G and Dilger WH (2009) Shear strength of slabs with double-headed shear studs in radial and orthogonal layouts. American Concrete Institute, ACI Special Publication (265): 499-510.

Broms CE (2007) Ductility of flat plates: comparison of shear reinforcement systems. ACI Structural Journal 104(6): 703-711.

BSI (British Standards Institution) (2005) BS EN 1992-1-1: Eurocode 2: Design of concrete structures. General rules and rules for buildings. BSI, London, UK.

Elgabry AA and Ghali A (1990) Design of stud-shear reinforcement for slabs. ACI Structural Journal 87(3): 350-361.

Fernández MR and Muttoni A (2009) Applications of the critical shear crack theory to punching of R/C slabs with transverse reinforcement. ACI Structural Journal 106(4): 485-494.

Ferreira MP, Melo GS, Regan PE and Vollum RL (2014) Punching of reinforced concrete flat slabs with double-headed shear reinforcement. ACI Structural Journal 111(2): 363-374.

fib (Fédération International du Béton) (2001) Punching Shear of Structural Concrete Slabs. fib, Lausanne, Switzerland, Bulletin 12, p. 307.

fib (2013) Model Code for Concrete Structures 2010. fib, Lausanne, Switzerland, p. 402.

Hoang LC (2006) Punching shear analysis according to the crack sliding model - slabs without shear reinforcement. Proceedings of the Danish Society for Structural Science and Engineering 77(3): 69-133.

Kinnunen S and Nylander H (1960) Punching of concrete slabs without shear reinforcement. Transactions of the Royal Institute of Technology, No. 158. Royal Institute of Technology, Stockholm, Sweden.

Lips S, Fernández MR and Muttoni A (2012) Experimental investigation on punching strength and deformation capacity of shear-reinforced slabs. ACI Structural Journal 109(1): 889-900.

Moreno CL and Sarmento AM (2013) Punching shear analysis of slab-column connections. Engineering Computations 30(6): $802-814$.

Musse TH (2004) Punção em Lajes Cogumelo: Fibras de Aco e Armadura de Cisalhamento [Punching in Flat Slabs: Steel Fibers and Shear Reinforcement]. Masters thesis, Escola de
Engenharia Civil, Universidade Federal de Goiás, Goiania, Brazil.

Muttoni A (1990) Die Anwendbarkeit der Plastizitätstheorie in der Bemessung von Stahlbeton [The Application of the Theory of Plasticity for the Design of Reinforced Concrete]. Institut für Baustatik und Konstruktion, ETH Zürich, No. 176, p. 158.

Muttoni A and Schwartz J (1991) Behaviour of beams and punching in slabs without transverse reinforcement. IABSE Colloquium, Stuttgart 62: 703-708. IABSE, Zürich, Switzerland.

Nielsen MP and Hoang LC (2011) Limit Analysis and Concrete Plasticity, 3rd edn., CRC Press, Boca Raton, FL, USA.

Nielsen MP, Braestrup MW, Jensen BC and Bach F (1978) Concrete Plasticity, Beam Shear - Shear in Joints Punching Shear. Danish Society for Structural Science and Engineering, Lyngby, Denmark.

Pop A (2014) Punching Shear Capacity of Reinforced Concrete Slabs with Transverse Reinforcement. Masters thesis, Department of Civil Engineering, Technical University of Denmark, Lyngby, Denmark.

Regan PE and Samadian F (2001) Shear reinforcement against punching in reinforced concrete flat slabs. The Structural Engineer 79(10): 24-31.

Seible F, Ghali A and Dilger WH (1980) Preassembled shear reinforcing units for flat plates. ACI Structural Journal 77(1): 28-35.

Trautwein L (2006) Punção em Lajes Cogumelo de Concreto Armado: Análise Experimental e Numérica [Punching in Reinforced Concrete Flat Slabs: Experimental and Numerical Analyses]. PhD thesis, Escola Politécnica da Universidade de São Paulo, Brazil.

Vaz APR, Gomes RG and Shehata LCD (2009) Study on minimum shear reinforcement of reinforced concrete flat slabs. IBRACON Structures and Materials 2(1): 1-24.

Zhang JP (1997) Diagonal cracking and shear strength of reinforced concrete beams. Magazine of Concrete Research 49(178): 55-65.

\section{WHAT DO YOU THINK?}

To discuss this paper, please submit up to 500 words to the editor at journals@ice.org.uk. Your contribution will be forwarded to the author(s) for a reply and, if considered appropriate by the editorial panel, will be published as a discussion in a future issue of the journal. 